\title{
Gamificación en la universidad II: aprendemos a divertirnos enseñando. Se divierten aprendiendo
}

Teresa San-Miguel, Javier Megías y Eva Serna

Departament de Patologia, Facultat de Medicina i Odontologia, Universitat de València. Teresa SanMiguel (teresa.miguel@uv.es), Javier Megías (javier.megías@uv.es), Eva Serna (eva.serna@uv.es)

\begin{abstract}
After the success last year using gamification as a motivating method in the degree of Biomedical Engineering (UV-UPV), we introduce it this year in degree in Podiatry $(U V)$. On the basis of the results of our first study, we focus on the use of Kahoot application in order to improve our students' motivation and subsequently, their califications. Despite the short timeexperience, the improvement in academic results has been evident. Although it could be due to many causes, it has been influenciated by this action. In addition, during the development of this type of activity the involvement and fun of our students does not cease to amaze us. They enjoy their successes and also their failures. We enjoyed with an spectacular feedback, which was almost non-existent during the classic class format.
\end{abstract}

Keywords:gaming, KAHOOT, motivation, TIC, m-learning

\section{Resumen}

Tras el éxito el curso pasado de la gamificación como método motivador en el grado de Ingeniería Biomédica (UV-UPV), utilizamos el método este año en el grado en Podología (UV). A la luz de los resultados del primer estudio nos centramos en el uso de la aplicación Kahoot, para tratar de mejorar la motivación de los estudiantes hacia nuestra asignatura, y en consecuencia, sus calificaciones. A pesar de lo corta que es la experiencia, hemos obtenido una importante mejora en el rendimiento, que si bien puede atribuirse a diveresas causas, en parte ha sido influenciada por esta iniciativa .Durante el desarrollo de este tipo de actividad no deja de sorprendernos la implicación y diversión de nuestros estudiantes. Ellos disfrutan de sus aciertos y también de sus fallos. Nosotros disfrutamos de un feedback espectacular, que era casi inexistente con el formato clásico de clase.

Palabras clave: ludificación, gamificación, KAHOOT, motivación, TIC, mlearning 


\section{Introducción}

La lección magistral resulta increíblemente útil cuando se cumplen dos premisas: la primera es que el orador domina a la perfección, no sólo la materia a transmitir sino también los puntos fuertes de la misma. La segunda, el tema ha de ser interesante para el receptor. Cuando enseñamos en los primeros cursos de un grado universitario, nos enfrentamos entre otros problemas, a que la materia, bien por su generalidad o bien por su concreción, puede quedar lejos del campo de proyección profesional que ha gestado el estudiante en su mente. Para paliar este problema, los profesores no podemos ser meros transmisores de conocimiento; en la medida de lo posible debemos investigar y trasladar al alumno la utilidad futura que tendrá interiorizar los conocimientos que queremos hacerle llegar. El Espacio Europeo de Educación Superior (EEES) insta al docente a mejorar sus técnicas pedagógicas, y a implementar las nuevas tecnologías en su día a día (Tejedor 2007).

Si bien ya es cotidiano el apoyo visual mediante presentaciones informatizadas, cada vez más, recurrimos a otros recursos multimedia, como vídeos, archivos de tipo .gif y otras animaciones, que incorporan audio además de imagen, para captar la atención y el interés de nuestra audiencia. Aún así, en una sociedad altamente hiperestimulada, la lucha contra las distracciones en el aula, está en el día a día. El estudio NMC Horizon Report 2016 Higher Education Edition, propone las estrategias basadas en el Bring Your Own Device (BYOD) para atajar este problema. Con ella, se pretende que ese ordenador portátil que cada vez más alumnos llevan, o ese teléfono móvil con el que se distraen, se introduzca en las vías de enseñanza-aprendizaje. La clave: mientras utilizan el teléfono con una aplicación para aprender o para aprender jugando, no pueden estar utilizándolo para otros fines. De hecho, la importancia de este diseño pedagógico en la educación actual, ha derivado en el desarrollo de toda una rama del conocimiento, englobada en el llamado m-learning o mobile-learning, fundamentado básicamente en el uso de dispositvos móviles (teléfonos, tabletas u ordenadores portátiles) en la docencia. De esta manera, KAHOOT entra en escena (https://kahoot.it/).

El programa KAHOOT permite, como ya describimos en nuestro anterior trabajo (SanMiguel 2016), elaborar concursos en línea, de una manera rápida y sencilla. Ludifica el aprendizaje pues la resolución del test se hace de manera interactiva: aparecen en pantalla las respuestas de los estudiantes representadas en gráficos de barras (figura 1) y ese feedback inmediato, indique acierto o error, incentiva al estudiante a seguir mejorando durante las posteriores preguntas del concurso (Pintor 2014). Tras cada pregunta, ordena a los participantes por la rapidez en acertar la pregunta y son varios los trabajos que describen la influencia sobre la motivación que tiene introducir puntuaciones en los juegos de aula de manera análoga a como lo hacen los videojuegos (Cortizo 2011, Mauricio 2015).

La motivación del estudiante es un elemento esencial para el aprendizaje, por ello pretendemos utilizar la tecnología KAHOOT con nuestros alumnos de Biología Celular y Tisular de primer curso del grado de Podología (UV). Se trata de un grado con estudiantes de muy diversas procedencias (PAU desde Bachiller, desde Ciclos Formativos de Grado Superior, para mayores de 25, para mayores de 50, numerosos segundos titulados etc). La asignatura Biología Celular y Tisular constituye una herramienta sobre la que construir el

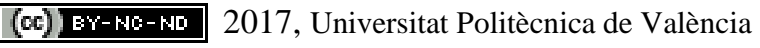


aprendizaje de las siguientes materias que encontraran durante la carrera, pero sus contenidos quedan aparentemente muy distantes de la práctica profesional que desempeñará el podólogo, por lo que mejorar su motivación es un aspecto que necesitamos trabajar para que los alumnos integren los contenidos académicos, cognitivos y procedimentales que deseamos en ellos y puedan sacar provecho de ellos en los siguientes cursos del grado.

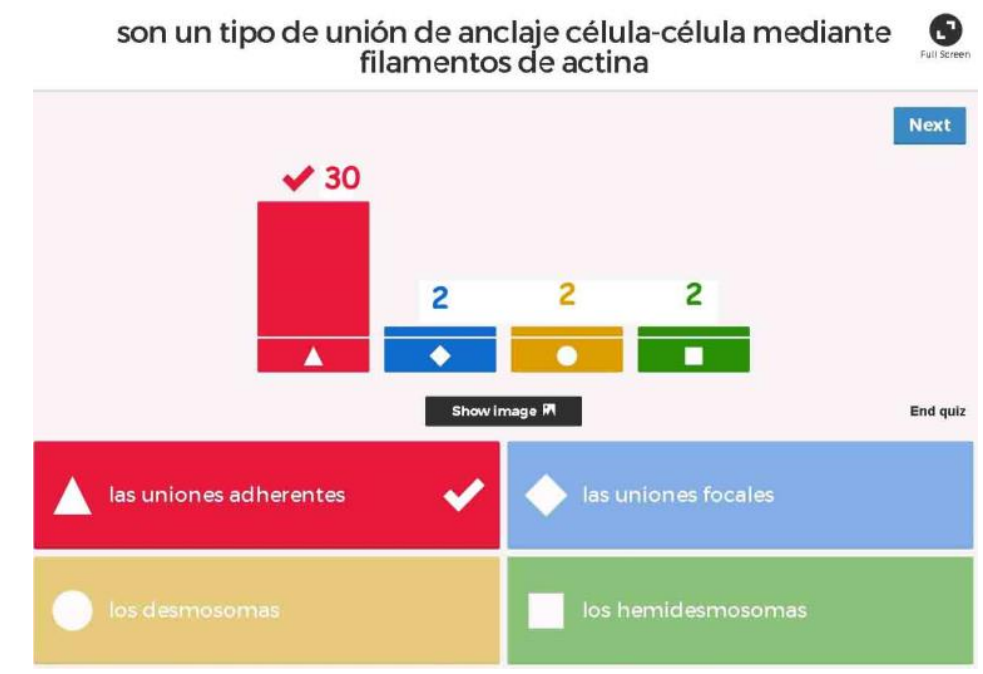

Fig. 1. Representación del resumen de resultados en gráficos de barras que muestra KAHOOT tras cada pregunta del concurso. Permite detectar respuestas erróneas que los alumnos escogen y explicarlas antes de proseguir con el concurso.

\section{Objetivos}

El objetivo principal de nuestra experiencia es mejorar el rendimiento de la sesión de repaso de la asignatura Biología Celular y Tisular, de 2 horas de duración. Con ello, pretendemos mejorar el rendimiento global en la asignatura. Esta sesión, tradicionalmente destinaba:

- Una hora a remarcar los aspectos que por nuestra experiencia entrañan mayores dificultades

- Una hora a resolver dudas concretas de los estudiantes. Esta hora no se usaba completa, ya que sólo los alumnos más precavidos llevaban dudas preparadas y el resto manifestaba escasa motivación e interés.

Para lograr nuestro objetivo, nos marcamos 5 subobjetivos:

1. Programar 2 mini-test con el programa KAHOOT

2. Romper con la ausencia de participación en la sesión de repaso de la asignatura

3. Ilustrar planteamientos diferentes sobre los contenidos teóricos de una forma práctica y visual

4. Cambiar el uso distractivo de teléfonos móviles y ordenadores portátiles a un uso aplicado al aprendizaje

5. Valorar el rendimiento académico frente al curso anterior. 


\section{Desarrollo de la innovación}

La experiencia se llevó a cabo en la sesión de repaso de la asignatura, a la que asistieron 36 alumnos (el 50\% de los matriculados). Con 7 días de antelación, se les informó de que parte de dicha sesión se destinaría a una actividad dinámica. Se prepararon 2 cuestionarios KAHOOT, uno de nivel básico y uno de nivel medio.

Atendiendo a descripciones de problemas de conectividad a la red cuando es elevado el número de estudiantes que entran en una sala de KAHOOT, se organizó a la clase en 10 grupos de 3-4 personas, según la afinidad personal de los integrantes.

El primer concurso, que constaba de 10 preguntas de contenidos básicos, sirve para:

- comprobar los problemas de conectividad en caso de que los hubiera

- familiarizarse con el entorno de software

- $\quad$ aumentar el nivel de confianza a la hora de contestar

El segundo concurso constaba de 15 preguntas de nivel medio. En él se introducen imágenes y diagramas que obligan al estudiante a aplicar sus conocimientos para resolver las cuestiones. Además se remarcan aspectos que la experiencia nos indica que suelen tener confusos (figura 2).

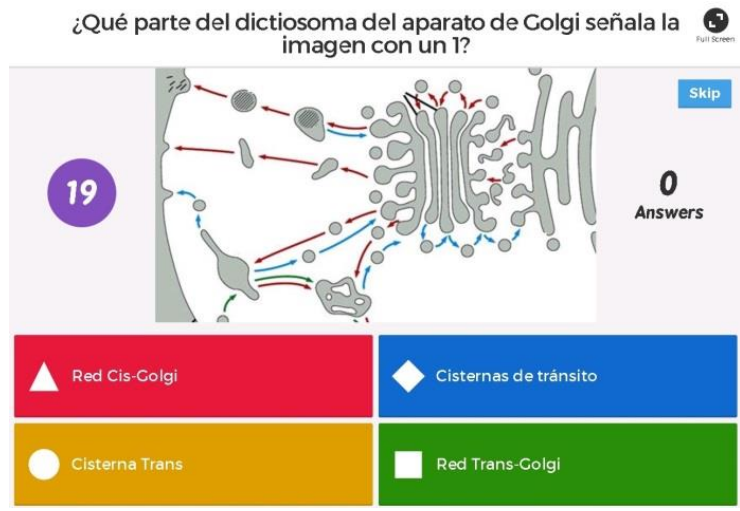

Fig. 2. Pregunta de un concurso con imagen. Permite utilizar imágenes similares a las empleadas en clase o invertidas, forzando al estudiante a replantearse su forma de aprendizaje.

Para conocer la valoración de los alumnos sobre la actividad realizada, más allá de nuestras propias impresiones, al finalizar la sesión se les proporcionó un breve cuestionario voluntario y anónimo. Las preguntas incluidas fueron:

- ¿Cuál es tu nivel de satisfacción con la experiencia de la práctica? Muy satisfecho-Satisfecho-Neutral-Insatisfecho-muy insatisfecho

- ¿Cómo consideras este tipo de actividades innovadoras como método para afianzar conceptos? excelente-bueno-indiferente-regular-malo

- ¿Encuentras práctico comenzar con una prueba de nivel básico? Muy útilbastante útil-indiferente-poco útil-nada útil

(cc) EY-NC-ND 2017, Universitat Politècnica de València 
- ¿Consideras que te ha resultado útil para conocer cómo se plantean cuestiones de la asignatura? Muy útil-bastante útil-indiferente-poco útil-nada útil

- ¿Prefieres realizar estas actividades de manera individual o grupal?

Por otra parte, aunque sea una corta experiencia y puedan ser diferentes los factores que influyen en los resultados académicos, comparamos las calificaciones del examen teórico en primera convocatoria del curso 2015-2016 con las obtenidas en la primera convocatoria tras nuestra experiencia KAHOOT en el presente curso 2016-2017.

\section{Resultados}

\subsection{Evolución de la web}

El primer resultado destacable es la evolución de la web KAHOOT desde febrero que la utilizamos en Ingeniería Biomédica (UPV-UV) a Diciembre que la hemos utilizado en Podología (UV): nuestra intuición nos llevó en la primera ocasión a formar grupos. La aplicación KAHOOT en estos meses, ha desarrollado ese modo de juego (figura 3); los usuarios ya pueden elegir si el tipo de concurso será individual o colectivo.

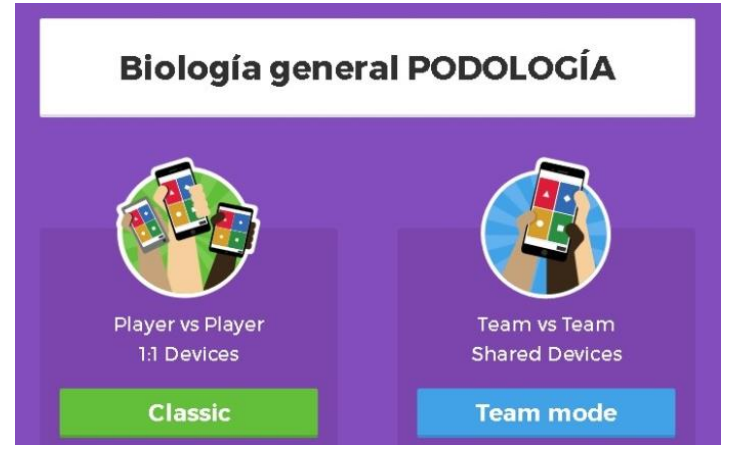

Fig. 3. Modos de juego ofrecidos por la aplicación. El Team mode es una reciente incorporación

\subsection{Valoración de los estudiantes}

El 100\% de los asistentes a la sesión participó de forma voluntaria en la actividad. Más allá de los resultados cuantificables, el entusiasmo de los participantes fue excepcional. Literalmente, querían hacer otro concurso más cuando acabamos con el segundo.

El nivel de satisfacción con la actividad fue muy elevado. Únicamente uno de los participantes que se encontraba satisfecho por el aspecto lúdico, no encontraba esencialmente útil el sistema para afianzar conceptos (figura 4). 


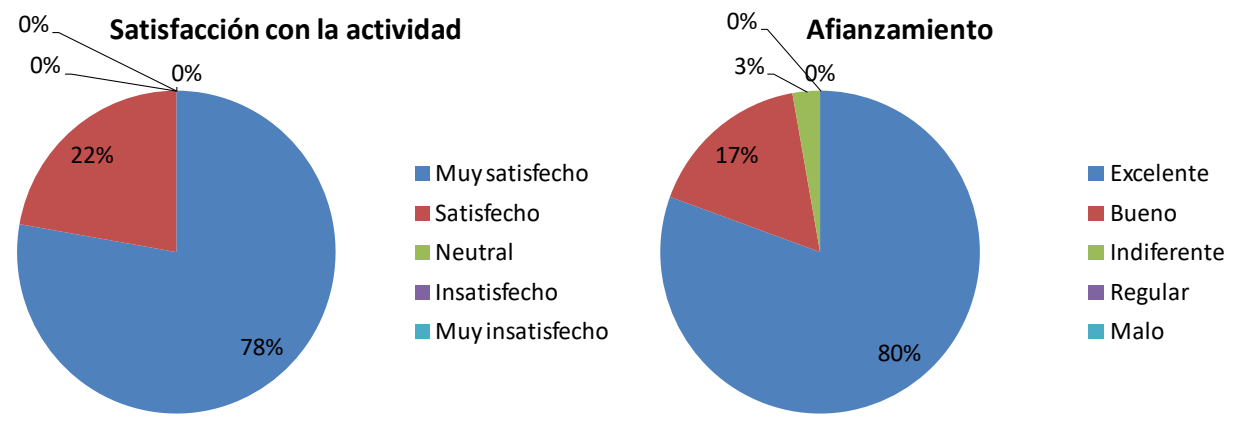

Fig. 4. Satisfacción de los estudiantes con la actividad y utilidad como método de refuerzo

Para valorar nuestra estrategia docente al planificar la actividad, los alumnos agradecen comenzar con una prueba de nivel básico, que les permite conocer la interfaz y hacerse con la dinámica del juego. Además, consideran muy útil conocer diferentes formas de preguntar conceptos que pueden resultar muy abstractos a nivel teórico

De cara a mejorar nuestra forma de plantear las actividades, preguntamos sobre realizar la actividad de manera grupal o individual y los alumnos insisten en que aprenden más trabajando en parejas o tríos que de manera aislada (figura 5).

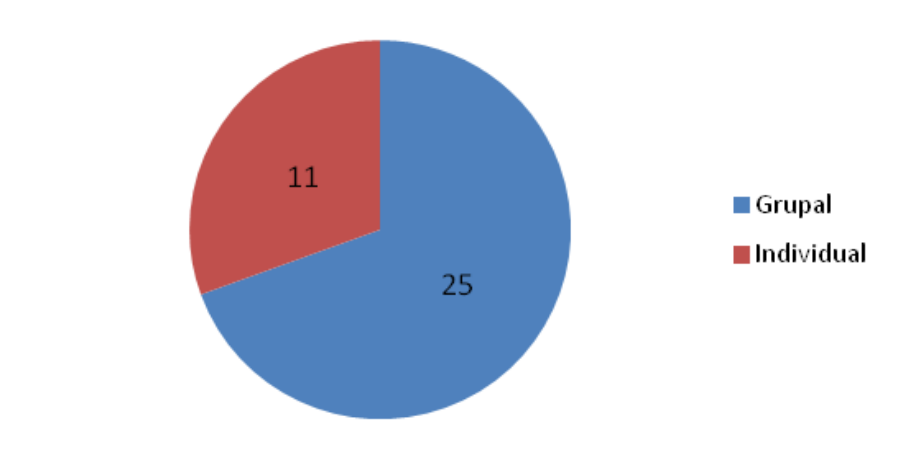

Fig. 5. Preferencia de los estudiantes por hacer la actividad de manera individual o grupal

\subsection{Mejora en las calificaciones}

Por último, comparamos los resultados académicos entre dos cursos consecutivos. La mejora ha sido evidente (figura 6). La proporción de aprobados ha subido desde el 32,5\% al $47,2 \%$ de aprobados en primera convocatoria. 


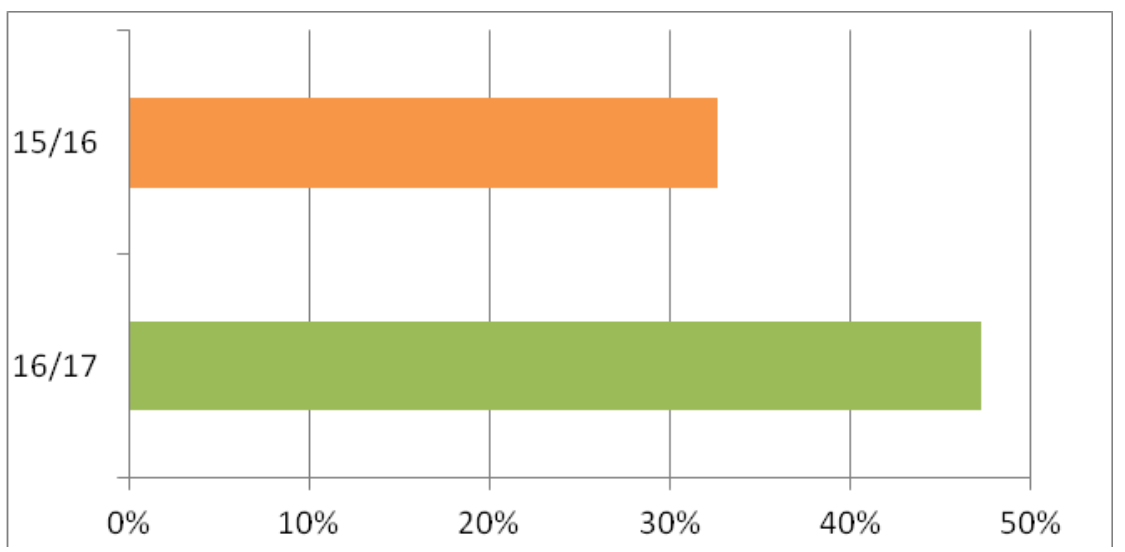

Fig. 6. Proporción de alumnos que alcanzan el aprobado en el examen teórico de Biología Celular en primera convocatoria en el curso 2015-2016 y 2016-2017

\section{Conclusiones}

La ludificación del aula universitaria es una alternativa novedosa en nuestra universidad y sobre todo, en la Facultad de Medicina y Odontología. Aunque parte del profesorado se muestra escéptico a este tipo de métodos en la formación universitaria, nuestros resultados en el grado de Podología concuerdan con trabajos previos en Odontología (Pintor Holguín 2014 y Serna 2015) e Ingeniería Biomédica (San-Miguel 2016) entre otros, mostrando que para los alumnos, jugar constituye una vía válida de adquirir conocimiento.

Uno de los aspectos más destacable fue la sorpresa que supuso el hecho de que fuera un juego, con su música, imágenes y puntuaciones. Los estudiantes se mostraban encantados. No obstante, esto incide en una de sus limitaciones, que sería el abuso. Mientras KAHOOT resulta francamente útil usado de manera esporádica, su uso continuado podría hacerle perder parte del efecto estimulante; este hecho a su vez, enfatiza el papel del docente en la elección y planificación de la iniciativa de manera minuciosa para optimizar los beneficios de su utilización, como ya han descrito otros autores (Kapp 2012, Zichermann 2011).

De las encuestas recopiladas, extraemos que todos los alumnos que participaron,se mostraron satisfechos o muy satisfechos con la actividad y únicamente un alumno se manifestó indiferente ante la utilidad de este tipo de dinámicas. Los resultados en la primera convocatoria de esta asignatura, son tradicionalmente malos, con tasas de aprobado que rondan el $30 \%$. Es evidente que son numerosos los factores que influyen en el rendimiento académico, y que no puede atribuirse a un cambio en una actividad, pero es muy destacable que este año en primera convocatoria, hemos alcanzado el aprobado en casi el 50\% de los matriculados. Este resultado es espectacular y estamos convencidos del efecto beneficioso que ha tenido la ludificación del aula en ello, y la remodelación de la sesión de repaso, logrando una atención y participación muy superior a la obtenida en cursos previos. Habría resultado ideal poder comparar los resultados entre los alumnos que participaron en la sesión de repaso frente a los que no asistieron, pero resultó imposible pues para incentivar su participación, se garantizó el anonimato de los participantes y la asistencia a la sesión era 
además, voluntaria. Por otra parte, el hecho de tener la opción de asistir a la sesión ya muestra una voluntad aumentada por parte de los estudiantes implicados, lo que constituiría también un sesgo; probablemente, las calificaciones de los asistentes sea intrínsecamente superior a la de los no asistentes, cada año, con independencia de la planificación que se le de a la sesión. No obstante, nos planteamos definir mejor todos estos parámetros para mejorar la valoración de estas actividades en cursos futuros.

Nuestra solución en ediciones anteriores a otra de las limitaciones de KAHOOT, que era la conectividad, había sido formar grupos. Ahora la propia plataforma propone la formación de grupos como método de juego. Podemos concluir que los estudiantes, al igual que nosotros, prefieren realizar estas actividades de forma grupal.

Queremos remarcar que uno de los elementos más didácticos que incluye este juego, es su pausa tras cada pregunta. El juego queda detenido sobre el gráfico de barras que muestra el número de participantes que han elegido cada una de las opciones. En ese momento, el docente puede aprovechar para explicar por qué la respuesta correcta es la que es, y sobre todo, incidir en el por qué de la incorrección de otras. Esto permite sobre una sóla pregunta, poder repasar diversos contenidos, de manera intercalada y con la atención de los estudiantes y así poder incidir positivamente sobre la asimilación y entendimiento de los conceptos.

Además de la increíble mejora en los resultados obtenidos en el examen, el desarrollo de la actividad fue muy estimulante. Comprobamos como la utilización de esta herramienta interactiva aumenta la participación de los estudiantes en la clase de repaso, aumenta la atención y favorece su implicación en el proceso de aprendizaje afectando positivamente en las calificaciones. Los alumnos querían más preguntas, más concurso, estaban francamente ilusionados respondiendo. Esta retroalimentación a su vez, nos motiva a nosotros como docentes a planificar de nuevo la actividad y a disponer de recursos que nos permitan adaptarnos a las demandas de nuestros estudiantes en función de cómo respondan ante nuestras intervenciones. Así, podemos aprovechar que los estudiantes se divierten aprendiendo, y nosotros podemos divertirnos con ellos, enseñando.

Podemos concluir que la gamificación con KAHOOT en el aula representa una herramienta potencial para impulsar cambios de actitud en los estudiantes y que en último término, esto repercute positivamente sobre el aprendizaje de los alumnos.

\section{Bibliografía}

CORTIZO PÉREZ, J.C.; CARRERO GARCÍA, F.; MONSALVE PIQUERAS, B.; VELASCO COLLADO, A.; DÍAZ DEL DEDO, L.I. y PÉREZ MARTÍN, J. (2011). "Gamificación y Docencia: Lo que la Universidad tiene que aprender de los Videojuegos". En: Retos y oportunidades del desarrollo de los nuevos títulos en educación superior. VIII Jornadas Internacionales de Innovación Universitaria. Universidad Europea de Madrid (2011 Madrid). Disponible en <http://hdl.handle.net/11268/1750> 
KAHOOT. Wang, A.I.; Brand, J. ; Brooker, J. y Versvik, M. (2013). Norwegian University of Science and Technology (NTNU). Trondheim, Noruega (Høgskoleringen 1, 7491 Trondheim, Noruega)

KAPP, K.M. (2012). The Gamification of Learning and Instruction: Game-Based Methods and Strategies for Training and Education. San Francisco, CA: John Wiley

MAURICIO, M.D.; SERNA, E. y VALLES, S.L. (2015). "Experiencias en la aplicación de la gamificación en $1^{\circ}$ Curso de Grado de Ciencias de la Salud”. En: Congreso de Innovación Educativa $y$ Docencia en Red. Universitat Politècnica de València (2015 Valencia). Disponible en <http://ocs.editorial.upv.es/index.php/INRED/>

NMC and the EDUCAUSE Learning Initiative (ELI). NMC Horizon Report - 2016 Higher Education Edition <http://www.nmc.org/publication/nmc-horizon-report-2016-higher-education-edition> [Consulta: 1 de abril de 2016]

PINTOR HOLGUÍN, E.; GARGANTILLA MADERA, P.; HERREROS RUIZ VALDEPEÑAS, B. y LÓPEZ DEL HIERRO, M. (2014). "Kahoot en docencia: una alternativa práctica a los clickers". En: XI Jornadas Internacionales de Innovación Universitaria. Educar para transformar. Universidad Europea de Madrid (2014 Madrid). Disponible en 〈http://hdl.handle.net/11268/3603>

SOCRATIVE. MasteryConnect. Salt Lake City, UT (222 South Main, Suite 200. Salt Lake City, UT 84101, USA)

SERNA, E.; MAURICIO, M.D.; SAN-MIGUEL, T. y MEGÍAS, J. (2016). "Experiencia de gamificación en Docencia Universitaria: aprendizaje activo y entretenido". En: Congreso de Innovación Educativa y Docencia en Red. Universitat Politècnica de València (2016 Valencia). Disponible en <http://ocs.editorial.upv.es/index.php/INRED/INRED2016/paper/view/4292>

SAN-MIGUEL, T.; MEGÍAS, J. y SERNA, E. (2016). "Gamificación en la universidad: una experiencia basada en el "bring your own device" en educación superior". En: Congreso de Innovación Educativa y Docencia en Red. Universitat Politècnica de València (2016 Valencia). Disponible en <http://ocs.editorial.upv.es/index.php/INRED/INRED2016/paper/view/4397>

TEJEDOR, F.J. Y GARCÍA-VALCÁRCEL, A. (2007). "Causas del bajo rendimiento del estudiante universitario (en opinión de los profesores y alumnos). Propuestas de mejora en el marco del EEES". Revista de Educación, vol. 342, p. 443-473

ZICHERMANN, G. Y CUNNINGHAM, C. (2011). Gamification by Design: Implementing Game Mechanics in Web and Mobile Apps. Cambridge, MA: O'Reilly Media 